\title{
History of Japanese medical education
}

Hirotaka Onishi

\author{
Department of International Cooperation for Medical Education, International Research Center for Medical Education, \\ The University of Tokyo, Tokyo, Japan
}

Since medical education programs in Korea and Japan seem to mutually influence each other, this review article provides a history of Japanese medical education, focusing on the way in which it influenced and was influenced by Korean medical education. In the late 19th century, the University of Tokyo established the core medical school, disseminating its scholarship and system to other medical schools. In the early 20th century, the balance between the quality and quantity of medical education became a new issue; in response, Japan developed different levels of medical school, ranging from imperial universities to medical colleges and medical vocational schools. After World War II, all of Japan's medical schools became part of the university system, which was heavily regulated by the Ministry of Education (MOE) Standard for the Establishment of Universities. In 1991, MOE deregulated the Standard; since 2000, several new systems have been established to regulate medical schools. These new approaches have included the Model Core Curriculum, 2-year mandatory postgraduate training, and a medical education accreditation system. Currently, most medical schools are nervous, as a result of tighter regulatory systems that include an accreditation system for undergraduate education and a specialty training system for postgraduate education.

Key Words: Medical education, Japan, History

\section{Introduction}

In every country, academic medicine is highly dependent on the national culture and changing it can be very difficult [1]. East Asian countries share a similar cultural background, based on Confucianism; Zhang et al. [2] in 2005 have shown that Korea and Japan share values that are closer to each other than to the values of China or Taiwan. Understanding the history of medical education may shed light on the context, causes, and results of various events in both societies. This inves- tigation of medical education systems in Korea and Japan reveals many similarities, including struggles to improve clinical clerkships and the weakness of small group discussions. The history of Japanese medical education may also be useful for international readers, especially those from East Asian countries.

Historically, the Korean medical education system was influenced by Japan because Korea was under Japanese rule between 1910 and 1945. After World War II (WWII) ended in 1945, the two countries ran their medical education systems separately. However, these two close neighbors continued to be aware of each other (cur-
Received: November 7, 2018 • Revised: November 12, $2018 \bullet$ Accepted: November 15, 2018 Corresponding Author: Hirotaka Onishi (https://orcid.org/0000-0002-6979-1088) Department of International Cooperation for Medical Education, International Research Center for Medical Education, The University of Tokyo, 2F Igakubu-sogochuokan, 7-3-1 Hongo, Bunkyo-ku, Tokyo, 113-0033, Japan

Tel: +81.3.5841.3534 Fax: +81.3.5841.0254 email: onishi-hirotaka@umin.ac.jp
Korean J Med Educ 2018 Dec; 30(4): 283-294. https://doi.org/10.3946/kjme.2018.103 eISSN: 2005-7288

(C) The Korean Society of Medical Education. All rights reserved. This is an open-access article distributed under the terms of the Creative Commons Attribution Non-Commercial License (http:// creativecommons.org/licenses/by-nc/3.0/), which permits unrestricted non-commercial use, distribution, and reproduction in any medium, provided the original work is properly cited. 
rently, Japan may be more conscious of Korea). For example, many medical educators heatedly discussed whether to incorporate structured clinical assessments into the national medical license examination and to implement graduate-entry medical school programs. After observing the Korean implementation program and its subsequent results, Japanese medical educators opted not to make these changes. Although a system for accrediting medical faculties was implemented in Korea before 2000, the Japan Accreditation Council for Medical Education (JACME) did not receive accreditation from the World Federation of Medical Education (WFME) until 2017.

This paper provides an overview of the history of Japanese medical education from the prewar period to the present day, both to reflect on curricular transitions and also to analyze major issues that may also affect other countries.

\section{The introduction of Western-style med- ical education}

Japan's national system of medical education began in the early 19th century; it included medical faculties established by provincial schools, independent medical schools established by the feudal government, and a system for studying abroad [3]. During this period, 'Western studies,' based on education in the Netherlands, the United Kingdom, Germany, and France became a trend. The medical sciences, including basic medicine, gradually became educational subjects.

The Kanda Otamagaike Smallpox Vaccination Office became part of the government in 1858. In 1870, it was reformed to become the first government-run Westernstyle medical school (igaku-sho), under the name 'Daigaku To-ko' (Eastern college). After much discussion about whether the German or British system should be used as a model, the government invited Drs. Müller and Hoffmann, German medical teachers, to Japan in 1871. In 1872, they developed a new curriculum that included a 3 years of preparatory school and a 5-year medical course taught mainly in German [4]. Daigaku To-ko was renamed 'Tokyo Igakko (medical school)' in 1874; in 1875, it applied to introduce a new course taught in Japanese. Although this was the first government-run medical school, the number of public (prefectural and municipal as well as government-run) medical schools increased to 30 by 1880 .

In 1877, the new government founded Japan's first university, the University of Tokyo. It consisted of four faculties: law, science, literature, and medicine [5]. In 1886, its name was changed to the Imperial University in accordance with an Imperial University Decree. In 1893, the Imperial University adopted an academic department system in which faculty members were responsible for offering students instruction and the opportunity to explore various specialized fields [6]. Imperial universities of this period offered compulsory classes assessed using the grade system; there were only a few selective courses.

A Medical Act in 1874 established a qualification system for doctors [7]. The first examination for a medical practice license was conducted in 1875; the nationwide unified examination system was launched in accordance with the regulation of physicians' examinations in 1879. Adding regulations related to higher education, the High School Decree and Vocational School Decree were launched in 1903 and 1894, respectively. Although high schools were positioned as preparatory schools for the Imperial Universities, they were also regarded as institutes of higher education until 1901. Medical faculties were therefore established at five high schools. Later, several private vocational schools 
appeared, which referred to themselves as universities.

The launch of medical education in Japan was influenced by the German system, since the University of Tokyo had German professors in its medical school. A hierarchical system was therefore established to disseminate academic knowledge and standards to other medical schools. One major hidden agenda was the need to maintain the consistency of Western medicine, separating medical education from previous practices influenced by complementary and alternative medicine. Policymakers in this era appear to have been successful, as their objectives were fulfilled, leaving room for traditional practitioners to maintain their practices. One weakness of this system may have been that the historical medical schools had too much influence over the whole medical education system.

\section{Between quality and quantity}

In 1918, a general system for universities was established by means of the University Decree and new High School Decree [8]. These decrees pushed universities to make decisions about abolishing the grade system, introducing the credit hour system, and offering elective courses. Preparatory schools were converted into high schools. In addition, all but two of the established medical vocational schools were upgraded to universities.

In the early 1920s, a movement to establish new private medical vocational schools emerged, in response to concerns that unifying medical education within universities might produce only proud, high-status university physicians and might actually decrease the number of physicians working in villages. In addition to the two existing private medical vocational schools, seven new schools were established between 1925 and
1928. Furthermore, Japan began its wartime regime in 1939 and the shortage of physicians became an emerging issue. As a result, seven imperial universities and six government medical colleges added temporary universityaffiliated medical vocational schools. Five new government-run medical vocational schools, along with fourteen prefectural and municipal schools (including one affiliated to a public medical college), and four private schools (including three affiliated to a private medical faculty) were built before 1945 .

In the early 20th century, Japanese imperialism was expanding rapidly. As Japan's territories expanded, the quantity of medical education and the resulting number of medical practitioners seemed to become more important than ever before. Since medical education combined the characteristics of vocational development with those of research-oriented higher education, expanding the medical education system from the imperial universities to medical colleges and medical vocational schools was a wise way to balance the competing goals of preserving the status of imperial universities, while also increasing the number of physicians at different levels of the various systems.

\section{The overseas expansion of the Jap- anese medical education system}

After the establishment of the Governor General of Taiwan in 1895, Japan expanded its overseas territories. The Taihoku（台北, Taipei) Hospital Medical Lecture Center was established in 1897, followed by the Governor General Taihoku Medical Vocational School (offering a 4-year curriculum) in 1927; Taihoku Imperial University established its Faculty of Medicine in 1936 (3 years of preparatory school+4 years of medical school) [9]. A vocational medical school was also established in 
Taipei in 1919, under the Governor General. It was converted into a vocational medical school affiliated with Taipei Imperial University in 1936. In Taiwan, these two medical schools were still operating when WWII ended.

In Korea, the Governor General of Korea was established in 1910; the Daikan (大韓, Daehan in Korean) Clinic was renamed the Governor General Clinic. It took over the affiliated medical school's educational function [9], which was upgraded to the 4-year Keijo（京城, Kyungsung) Medical Vocational School in 1916. Korean enthusiasm for higher education rose sharply after Japan enacted the University Decree in 1918, introduced a Keijo Imperial University preparatory school entrance examination in 1924, and established a Faculty of Medicine at Keijo Imperial University in 1926 [10]. The preparatory school initially offered a 2-year curriculum but this became a 3-year curriculum in 1934. When WWII ended, Korea had Faculty of Medicine at Keijo Imperial University and five other vocational medical schools: a government school in Seoul, two provincial schools in Taikyu (大邱, Daegu) and Koshu (光州, Gwangju), and two private schools, Severance and Keijo Women's. In North Korea, two vocational medical schools were established at Heijo (余袞, Pyongyang) in 1933 and Kanko (咸興, Hamhung).

In Manchuria and the Kwantung Leased Territory, more than ten medical schools were established, including several medical colleges [9]. However, many medical schools did not have a long history of physician development. In Karafuto (樺太, Sakhalin) Prefecture, a medical lecture center affiliated with Toyohara（豊原, Yuzhno-Sakhalinsk) Hospital was established in 1941, under the direct management of the Japanese Ministry of Education [9]. Japanese medical schools were also established in the Philippines, Indonesia, Malaya (currently Malaysia), and Burma (currently Myanmar) during the short period of time when these were mandated territories [9].

Although all of Japan's medical faculties, colleges, and vocational schools had 4-year curricula, only the imperial universities required applicants to complete preparatory school before enrolling; this was a requirement because fundamental studies were mandatory. Only Seoul and Taipei were given the status of imperial universities. Korea appears to have been very enthusiastic about education during this period, given that an Imperial University was established in Korea before Taiwan, which Japan had ruled at an earlier time.

\section{Postwar medical education system}

Dr. Sams, the Director of the Public Health and Welfare Bureau established by the Supreme Commander for the Allied Powers rebuilt various aspects of the public health infrastructure and initiated reforms, abolishing medical vocational schools, improving undergraduate medical education, reinstating the national medical license examination, and implementing a clinical practice training system [11]. Consequently, the number of medical schools (university medical faculties, medical colleges, and medical vocational schools) fell from 85 to 45. Imperial universities were downgraded to ordinary universities, and the number of students enrolled in medical schools, which exceeded 10,000 in 1945, decreased to 2,800. All of the administrative power that Japan had directed toward its overseas medical schools quickly disappeared.

The Basic Act on Education and School Education Act were enacted in March 1947; it came into effect in April 1947. In 1948, the University Standards Association issued its approved medical education standards. These standards stipulated the basic design of both the 2- to 
3-year preparatory course and the 4-year medical course. It also set out detailed standards for course subjects and class hours (Table 1). After the required courses were established, the remaining $9 \%$ of subjects were selective. Dr. Sams also targeted graduate entry requirements for medical schools, eventually settling on a 2-year preparatory course, followed by automatic promotion to a 4-year specialized medical course [12]. In 1954, medical education standards were redefined and course subjects and preparatory-course hours were specified. A grand design for medical education was formulated; it included a 6-year consecutive undergraduate curriculum, a 1-year system of internships for clinical rotation training, and a medical license examination. In 1956, the Standard for the Establishment of Universities was enacted as an Order of the Ministry of Education, Science, Sports, and Culture (MOE); it also

\begin{tabular}{lc}
\hline Table 1. Course Subjects/Class Hours under Medical & Education \\
Standard (Approved by the University & Standards \\
\multicolumn{2}{c}{ Association in 1948) [11] } \\
\hline \multicolumn{2}{c}{ Subjects } \\
\hline Basic medical science and social medicine \\
Anatomy \\
Physiology & 10 \\
Biochemistry & 6 \\
Pharmacology & 4 \\
Pathology & 4 \\
Microbiology (bacteriology) & 6 \\
Hygienic & 4 \\
Public health & 2 \\
Medical zoology & 4 \\
Forensic medicine & 2 \\
Clinical medicine & 2 \\
Internal medicine & \\
Psychiatry & 19 \\
Pediatrics & 2 \\
Surgery & 3 \\
Orthopedics & 9 \\
Dermatology and urology & 2 \\
Ophthalmology & 3 \\
Otolaryngology & 2 \\
Radiology & 2 \\
Gynecology & 1 \\
\hline & 4 \\
\hline
\end{tabular}

included a preparatory medical course.

In 1953, three problems were pointed out, involving the internship programs: poor practical training content, no guarantee of internship status, and financial hardship [13]. In 1967, a movement of medical students and residents to improve the treatment and payment of interns grew larger. Although its initial aim was to abolish the internship programs, it added efforts to block the national medical license examination. The internship system was abolished through a revision of the Medical Practitioners Act in 1968. In addition, a system for training clinical physicians was launched as a good-faith gesture. This system allowed physicians to train in medical faculties, university hospitals, and hospitals designated by the Minister of Health and Welfare for 2 years or more.

Meanwhile, Akita University, which suffered from a shortage of physicians, requested permission to establish a medical faculty. After this was agreed in 1970, many prefectures came up with requests to establish medical faculties. A political initiative to create a one-prefecture one-medical school system increased the number of medical schools from 46 in 1969 to 80 in 1979. Enrollment capacity increased from more than 4,000 to more than 8,000 [14]. It also became possible for medical faculties and colleges to freely design their curricula. The Tsukuba University Faculty of Medicine, newly established in 1973, featured an integrated curriculum for basic science and clinical medicine, along with the concept of a 6-year coherent education.

From the end of WWII until the 1980s, medical education in Japan was restructured and revived through American rule and assistance/influence. Enrollment fell just after WWII but increased again as it adjusted to the level of the economy. Medical education became an established academic area in the 1970s, after the Japan Society for Medical Education (JSME) was inaugurated 
in 1969. JSME sent many members on faculty development (FD) courses in Australia and disseminated up-todate information through its own FDs. This movement was regarded as helpful in maintaining the quality of medical education, while expanding the number of medical schools.

\section{Deregulation of the Standard for the Establishment of Universities}

The advisory panel for universities, set up within MOE in 1987, issued an official report on the improvement of university education' in February 1991. Alongside the report, MOE issued amendments in the form of ministerial orders to the Standard for the Establishment of Universities on July 1, 1991. The amendments repealed the segmentation of general and specialized education and the division between different general education subjects (such as the humanities, social studies, natural studies, foreign languages, and health and physical education) [15]. This so-called deregulation of the Standard for the Establishment of Universities was a courageous decision on the part of $\mathrm{MOE}$, aimed at enhancing every institute of higher education in the country.

MOE revised a few more specific aspects of the Standard for the Establishment of Universities. The system of pre-medical studies (shingaku katei) was abolished in faculties of medicine and dentistry. The previous rigid way of calculating academic credits for each subject was made more flexible. The number of full-time faculty members needed for each subject also became more flexible, reflecting the number of the students in each medical school. The upper limit for numbers of part-time faculty members was abolished. At the same time, each institute of higher education was obliged to implement a system of self-evaluation to improve its program, as the first step toward implementing a future accreditation system.

This was an important moment, when universities were forced to change their systems of administration. Although medical education has a vocational development perspective, all of the medical schools were under the governance of universities. Government had to delegate administrative authority to each university as an autonomic institute, allowing universities to better control their grants and accreditation systems.

\section{Drastic governmental reforms of colleges and universities in the 21st century}

Since 2001, MOE has changed its name to the Ministry of Education, Culture, Sports, Science, and Technology (MEXT), accelerated the structural reform of governmentrun universities, and issued a new policy, known as the 'Toyama Plan,' after the Minister who proposed it. The Toyama Plan addressed three points: the restructuring and integration of government-run universities, the introduction of managerial methodologies developed by the private sector, and the introduction of competitive principles and third-party assessment [16]. MEXT's forceful promotion of restructuring and integration resulted in the mergers of eight government-run medical colleges (Yamanashi, Fukui, Kagawa, Kochi, Shimane, Saga, Oita, and Miyazaki) with governmental universities in each prefecture to promote interdisciplinary education and research in 2002 and 2003; this initiative led to a drastic shake-out and to scrap-and-build reforms.

To change the internal policies and management of universities, MEXT enacted a piece of legislation, the National University Corporation Act, in July 2003. This Act converted all government-run universities into 
independent university corporations [17]. After the law was enforced in April 2004, government influence on each national university corporation became stronger, as MEXT acquired the right to designate a president for each corporation.

Competition among medical schools accelerated. One typical example was the Center of Excellence (COE) policy [18]. MEXT selected dozens of top research and educational programs and offered them enormous grants. The COE also applied to public (prefectural or municipal) and private universities and colleges. Many universities and colleges were concerned about MEXT's grading. Ironically, some faculty members began to lose their commitment to teaching because it was harder to demonstrate achievements in education than it was in research.

Since 2004, the Ministry of Health, Labor, and Welfare (MHLW) has implemented a 2-year mandatory postgraduate training system [19]. Previously, most graduates chose a department in their university hospital and began to train in their chosen specialty, such as dermatology or neurosurgery, as in the US system. In the new system, trainees have to rotate between major specialties, including internal medicine, pediatrics, emergency medicine, and community-based practice. This program has enabled trainees to become more confident in basic skills and clinical experience, ensuring better patient safety [20], However, the Association of Japanese Medical Colleges (AJMC) submitted a paper to MEXT, MHLW, and the Ministry of Internal Affairs and Communications, arguing that the new system could lead to a deterioration in community medical practice. The MHLW responded by holding a review meeting on the ideal clinical postgraduate training system [21]. This was needed to address the temporary lack of new medical graduates, especially in university hospital departments in 2004 and 2005.
Ten years after the deregulation of the Standard for the Establishment of Universities, government regulations for all universities, including medical schools, became much tighter. MHLW and MEXT launched a personnel exchange to promote better communication with each other. Some medical schools in non-urban areas have changed from a research-orientated stance to a community-oriented one. All medical school clinical departments had previously had substantial authority over postgraduate personnel issues; after 2004, this power was somewhat reduced.

\section{The Model Core Curriculum and the Common Achievement Test}

From 1996 to 1999, MOE’s Advisory Panel for Medical Studies and Practices for the 21st century continued discussions, issuing four reports. The first report $\mathrm{ex}^{-}$ plained the best way to nurture health professionals for 21st century, covering humanistic aspects, patientcenteredness, life-long learning, and global perspectives. [22]. The fourth report specified ways to improve undergraduate medical education, particularly through the careful selection and diversification of educational content [23]. To respond to the reports, the survey collaborators' team for a new vision of medical and dental education issued a report to improve medical and dental education in the 21st century; the report included a 'Model Core Curriculum (MCC)' [24]. The medical MCC, developed collaboratively by all of the medical schools, provided a basis for undergraduate medical education. Importantly, in each medical school, it should cover only two-thirds of the whole curriculum; the remaining one third had to be developed on its own.

The Common Achievement Test (CAT) was developed as an assessment system for the preclinical part of the 
MCC [25]. The pilot assessment was launched in 2002 and fully implemented in December 2005. All medical students had to take and pass the CAT before advancing to the stage of practical training at a clinical site. The CAT consisted of computer-based testing (CBT) and an objective structured clinical examination (OSCE). The CBT contains multiple choice questions and extended matching items. The OSCE consists of at least six stations, one station for the 10-minute medical interview and the other stations for a 5-minute physical examination or basic skills. To deal with all logistical tasks, the Common Achievement Test Organization was inaugurated as a third-party organization with the support of MOE in 2005.

Both the MCC and the CAT had a significant influence on medical schools in Japan. After the MCC was implemented, medical schools that followed the MCC framework found it easier to obtain large-scale educational grants from MEXT. In relation to the CAT, external examiners would learn the educational atmosphere of each medical school, creating an atmosphere of mutual evaluation. When students apply for training hospitals in their final year, some hospitals tended to ask for CBT scores, knowing that there is a high correlation between CBT and license examination scores. Naturally they preferred to avoid applicants who seemed likely to fail the license examination.

\section{The new accreditation system with international recognition}

As for the accreditation system in general, the institutional accreditation system was introduced in 2004, with the revision of the School Education Act [26]. No accreditation system was established specifically for the field of medical education. After the Educational Com- mission for Foreign Medical Graduates (ECFMG) in the United States made its announcement in September 2010 [27], the AJMC set up a committee to review quality assurance in medical education, beginning a discussion about its 2011 response. MEXT appointed a project team to promote and reform universities in 2012; it began research on establishing an evaluation system specifically for medical education [28].

In the project, the WFME's global standard for undergraduate medical education was translated into Japanese with partial modifications to match the situation in Japan; it was then disclosed as a standard for evaluation. In December 2015, all 80 medical schools became members and founded the JACME, with the cooperation of MEXT and AJMC. In addition, the trial evaluation period was repeated until fiscal year 2016; in March 2017, JACME was certified by WFME [29].

JACME officially carried out its evaluation from April 2017 onwards. Although this accreditation is not based on the Japanese School Education Act, medical schools accredited by JACME are able to register with Foundation for Advancement of International Medical Education and Research and graduates from accredited medical schools are eligible to apply to the ECFMG. Certification is valid for 7 years if full certification is obtained, and for 3 years if certification is certified for a limited term. JACME does not have the authority to place medical schools on probation or to terminate such schools.

\section{The recent situation in Japanese med- ical education}

Every medical school that offers undergraduate medical education seems to be nervous about the JACME accreditation system. When they think about making 
changes to their curricula or systems, most of these changes reflect the JACME evaluation standard. This nervousness increased after the Faculty of Medicine of Osaka City University received a limited-term accreditation [30]. Medical schools renewed their efforts to conform to the Core Curriculum, government policies, and the AJMC.

There were no changes to the 2-year mandatory general postgraduate training system after 2004. However, the specialty training system that covers the following 3 years or longer is currently facing a chaotic situation. Previously, in Japan, most specialty training and certification systems were provided by societies or associations in each specialty. In 2002, the Japanese Board of Medical Specialties was established to improve quality and the system of specialists. Its main body was the 2014 successor to the Japanese Medical Specialty Board (JMSB). Although representatives of the organization were approved in 18 basic areas (including internal medicine and surgery), no representative was appointed in the area of general practice, due to the struggle for supremacy between the Japan Medical Association, the Japan Primary Care Association, and other similar bodies. Although the JMSB announced that new specialist training programs would be initiated in April 2017, these programs were postponed because the JMSB could not reconcile opposing opinions in 2016. The programs finally began in April 2018. Only the specialty training program for general practice is directly managed by the JMSB; other programs formally registered at the JMSB are actually managed by the named representative from each specialty society or association, including the Japan Society of Internal Medicine, the Japan Surgical Society, and other specialist groups. One of the most troubling issues is the lack of disclosed information about the general practice examination planned for the spring of 2021.

\section{Conclusion}

The reform of Japanese medical education has always seemed very slow, but the reason for this can be appreciated by adopting a historical viewpoint. Since Japanese medical education has been heavily influenced by the German and US systems, an overview of the historical context will help to explain the current situation.

Several points can be made about medical education policies. First, a medical education policy should be aligned with the overall policy governing medical practice. In the prewar era, the key issues involved Western medicine versus traditional Oriental medicine, the relationship between undergraduate medical education and the licensing system, and how best to expand high-quality medical education. In the postwar era, the key issues were the reform and standardization of medical education, the establishment of a postgraduate training system, and the government's new regulatory system for budget allocations, accreditation, and specialty training quality. Since 2000, medical education policy has been increasingly influenced by the movement to provide patient safety and measures to address the super-aging society.

Second, from the government's point of view, controlling the power of medical schools seems an important issue. The major stakeholders for medical education are the ministries responsible for education and health, the Japan Medical Association, medical schools, and society. In the past 20 years, the power of the Japan Medical Association has diminished and the voices of society have grown louder. One recent example is a case of fraud perpetrated by an MEXT officer, who asked the President of Tokyo Medical University to admit his son through a backdoor. Almost every day, in October 2018, 
the mass media reported that a thorough investigation by MEXT had revealed that young male applicants were given extra points, increasing their original scores. Some women activists demonstrated to protest this unfairness; more than 100 applicants were excluded by such unfair admission procedures during the past 2 years. Those who were excluded have been approved for entrance in the 2019 spring batch. Several other medical schools have voluntarily announced that similar cases of unfairness have been found in their systems. During these decades, admission to medical schools has become much more competitive and public interest in this issue seems very high. MEXT is using staff fraud to open a Pandora's box of unfair admission procedures at medical schools.

Third, the expansion of full-time faculty members in medical education has become a silent trend during the past 20 years. Previously, medical education was the purview of professors who had published enough articles in their research fields. A recent increase in undergraduate and postgraduate teaching requirements and the medical schools' need to balance medical services, education, and research have sparked a major drive to increase full-time medical educators. At the same time, internationally, more graduate school programs are offering medical and health professional education degrees at the Master's degree or Doctor of Philosophy level, even though MEXT has not approved such programs in Japan [31]. As the first graduate of such a Master's degree program, I would suggest that full-time faculty members in such positions should have certain level of training in education.

ORCID:

Hirotaka Onishi: https://orcid.org/0000-0002-6979-1088

Acknowledgements: None.

Funding: None.
Conflicts of interest: No potential conflict of interest relevant to this article was reported.

Author contributions: Drafting, critical revision, and final approval for publication by $\mathrm{HO}$.

\section{References}

1. Haizlip J, May N, Schorling J, Williams A, Plews-Ogan M. Perspective: the negativity bias, medical education, and the culture of academic medicine: why culture change is hard. Acad Med. 2012;87(9):1205-1209.

2. Zhang YB, Lin MC, Nonaka A, Beom K. Harmony, hierarchy and conservatism: a cross-cultural comparison of Confucian values in China, Korea, Japan, and Taiwan. Commun Res Rep. 2005;22(2):107-115.

3. Umihara R. Medical education in the Edo Era. In: Sakai T, ed. History of Japanese Medical Education. Sendai, Japan: Tohoku University Press; 2012:1-33.

4. Kira S. Acceptance and dissemination of German medicine in the Meiji Era. In: Sakai T, ed. History of Japanese Medical Education. Sendai, Japan: Tohoku University Press; 2012:35-60.

5. Terasaki M. University reform: history, system, curriculum. Tokyo, Japan: Toshindo; 1999.

6. Ogawa T. A short history of medical education in Japan. Med Educ. 1972;3(1):6-9.

7. Sakai T. Public medical schools in the early Meiji Era. In: Sakai T, ed. History of Japanese Medical Education. Sendai, Japan: Tohoku University Press; 2012:61-113.

8. Amano I. University decree and physician development in the Taisho and Showa Eras. In: Sakai T, ed. History of Japanese Medical Education. Sendai, Japan: Tohoku University Press; 2012:149-185.

9. Izumi T. Medical schools in annexed territories. Osaka, Japan: Medical Review Co., Ltd.; 2009.

10. Umakoshi T. A study of the establishment of the pre- 
paratory department of the Keijo Imperial University in Korea under Japanese rule. Daigaku Ronshu. 1977;5: 135-155.

11. Fukushima O. Postwar system of reform for medical education. In: Sakai T, ed. History of Japanese Medical Education. Sendai, Japan: Tohoku University Press; 2012:213-245.

12. Nishimura S. Promoting health in Japan under the American occupation [1945-1952]: the design of the 8-year medical education program. Med Educ. 2013; $44(6): 421-428$.

13. House of Representatives, Japan. The 4th minutes of the 15th Committee on Health and Welfare on 10 March 1953. http://kokkai.ndl.go.jp/SENTAKU/syugiin/015/0790/ 01503100790019a.html. Accessed November 12, 2018.

14. Ojima A, Hori M. School of medicine, medical college in Japan. In: Japan Society for Medical Education, ed. Medical Education White Book 1986 Version. Tokyo, Japan: Shinohara Shuppan; 1986:6-15.

15. Ministry of Education, Science, Sports and Culture. Implementation of ministerial order of revising part of the Standard for the Establishment of Universities. http://www.mext.go.jp/b_menu/hakusho/nc/t1991062400 1/t19910624001.html. Published 1991 June. Accessed November 12, 2018.

16. Ministry of Education, Culture, Sports, Science, and Technology, Japan. Policy for restructuring universities (government-run universities). http://www.mext.go.jp/b_ menu/ shingi/gijyutu/gijyutu8/toushin/attach/1331038.htm. Published June 2001. Accessed November 12, 2018.

17. Ministry of Education, Culture, Sports, Science, and Technology, Japan. The National University Corporation Act. http://www.mext.go.jp/b_menu/houan/an/detail/1384226. htm. Published July 2003. Accessed November 12, 2018.

18. Ministry of Education, Culture, Sports, Science and Technology, Japan. The 21st century Center of Excellence Program. http://www.mext.go.jp/a_menu/koutou/ coe/05041401/004.htm. Published 2005. Accessed November 12, 2018.

19. Onishi H, Yoshida I. Rapid change in Japanese medical education. Med Teach. 2004;26(5):403-408.

20. Nomura K, Yano E, Aoki M, Kawaminami K, Endo H, Fukui T. Improvement of residents' clinical competency after the introduction of new postgraduate medical education program in Japan. Med Teach. 2008;30(6): el61-el69.

21. Ministry of Health, Labor, and Welfare. Coordinated opinions regarding clinical postgraduate training systems, etc. https://wuw.mhlw.go.jp/shingi/2009/02/dl/s0226-10a. pdf. Published February 2009. Accessed November 12, 2018.

22. Ministry of Education, Culture, Sports, Science and Technology, Japan. Developing health professionals to care for lives and health in the 21st century (The 1st report by panels on 21 st century medical science and practice). http://www.mext.go.jp/b_menu/shingi/chousa/ koutou/009/toushin/961201.htm. Published December 1996. Accessed November 12, 2018.

23. Ministry of Education, Culture, Sports, Science, and Technology, Japan. Developing health professionals to care for lives and health in the 21st century (The 4th report by panels on 21 st century medical science and practice). http://www.mext.go.jp/b_menu/shingi/chousa/ koutou/009/toushin/990401.htm. Published April 1999. Accessed November 12, 2018.

24. Research and Development Project Committee for Medical Education Programs, Ministry of Education, Culture, Sports, Science, and Technology, Japan. Model core curriculum for medical education: educational content guidelines. Tokyo, Japan: Ministry of Education, Culture, Sports, Science, and Technology; 2001.

25. Fukushima O. A nationwide medical and dental student evaluation system for entering clinical clerkships: computer-based testing and objective structured clinical 
examinations. Med Educ. 2002;33(2):83-87.

26. Kaneko M. Perspectives on accreditation. Daigaku Hyoka Kenkyu. 2013;12:5-13.

27. Educational Commission for Foreign Medical Graduates. ECFMG to require medical school accreditation for international medical school graduates seeking certification, beginning in 2023. https://www.ecfmg.org/forms/ 9212010.press.release.pdf. Published September 2010. Accessed November 12, 2018.

28. Nara N. Area-specific accreditation. In: Japan Society for Medical Education, ed. Medical Education White Book 2014 Version. Tokyo, Japan: Shinohara Shuppan
Shinsha; 2014:58-60.

29. Nara N. The history and vision of JACME: JACME newsletter. https://www.jacme.or.jp/pdf/web_jacme_newsletter _vol01.pdf. Published 2017. Accessed November 12, 2018.

30. Osaka City University Graduate School of Medicine and Faculty of Medicine. Area-specific accreditation in medical education. http://web.med.osaka-cu.ac.jp/education/ jacme.shtml. Accessed November 12, 2018.

31. Tekian A, Roberts T, Batty HP, Cook DA, Norcini J. Preparing leaders in health professions education. Med Teach. 2014;36(3):269-271. 